\title{
DYNAMICS OF AGE AND GENDER-DEPENDANT CORRELATES OF RECURRENT HEADACHE IN BANGLADESHI SCHOOLERS
}

\author{
C.S. Narayan ${ }^{1,2}$, K.S. Anwar ${ }^{3,4}$, M.A.H. Mollah ${ }^{5,6}$, S. Akhter ${ }^{5,7}$
}

${ }^{1}$ Child Neurology Division, Department of Paediatrics, ${ }^{2}$ Scientific Secretary,Bangladesh Society for Child Neurology Development and Disability(BSCNDD), Dhaka Medical College Hospital (DMCH), ${ }^{3}$ Epidemiology Unit, Dept. of Microbiology, Institute of Public Health (IPH), Govt. of Bangladesh, Dhaka, Bangladesh, ${ }^{4}$ Dept. of Microbiology, Hawtah Sudair Hospital, Riyadh, Saudi Arabia, ${ }^{5}$ Dept. of Paediatrics, ${ }^{6}$ Head, Neonatalogy, Dept. of Paediatrics, Dhaka Medical College Hospital (DMCH), ${ }^{7}$ Posted under Director General of Health Services, Govt. of Bangladesh, Dhaka, Bangladesh

Objective: Study the trend and dynamics of age-and gender-dependant prevalence of headache $n$ schoolers and to determine if these attribute as plausible factors for recurrent headache.

Background: Magnitude of recurrent headache is not well explored in school-children (schoolers) particularly in developing countries, and not documented in Bangladesh, yet.

Design and/or methods: Cross-sectional population based respondent-dependent study following INternational Headache Soiety's ICHD-II (2004) recommened criteria.

Results: Overall-prevalence of Recurrent Headache among 1499 schoolers studied was 17\%; being few times more in pubertal (13-15) than pre-pubertal $(11-12)$ years-old children $(p<0.001)$. Migraine was observed in 55\% while Tension-Type-Headache in $20 \%$ demonstrating a steady-inclining-trend with age. Gender difference was obvious in migraine $(p<0.001)$ but not in tension-type $(p<0.31)$. Older-children $(\mathrm{OR}=8.75)$ and boys $(\mathrm{OR}=1.8)$ were at potential risk for migraine and tension type headache.

Conclusions: Since RHA connote serious public health implication(s) in Bangladeshi-schoolers, massawareness is imperative to prevent them from being chronic, psycho-socially handicapped and economically burdened. Further in-depth studies warrant data to examine its long-term risks/underlying factors. 